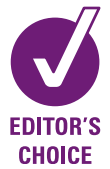

CHOICE

\title{
Treatment of ruptured and unruptured cerebral aneurysms in the USA: a paradigm shift
}

\author{
Ning Lin, ${ }^{1,2}$ Kevin S Cahill, ${ }^{1,2}$ Kai U Frerichs, ${ }^{1,2}$ Robert M Friedlander, ${ }^{3}$ \\ Elizabeth B Claus ${ }^{1,2,4}$
}

${ }^{1}$ Department of Neurosurgery, Brigham and Women's Hospital, Boston, Massachusetts, USA ${ }^{2}$ The Brigham and Women's Hospital, Harvard Medical School, Boston, Massachusetts, USA

${ }^{3}$ Department of Neurological Surgery, University of Pittsburgh Medical Center, Pittsburgh, Pennsylvania, USA

${ }^{4}$ Department of Epidemiology and Public Health, Yale University School of Medicine, New Haven, Connecticut, USA

\section{Correspondence to} Dr Ning Lin, Department of Neurosurgery, Brigham and Women's Hospital, 75 Francis Street, Boston, MA 02115, USA; nlin1@partners.org

Part of the study was presented at the 7th International Stroke Congress in Seoul, South Korea, 2010

Received 6 February 2011 Revised 24 April 2011 Accepted 6 May 2011 Published Online First 23 June 2011

\begin{abstract}
Background Integration of data from clinical trials and advancements in technology predict a change in selection for treatment of patients with cerebral aneurysm.

Objective To describe patterns of use and in-hospital mortality associated with surgical and endovascular treatments of cerebral aneurysms over the past decade.
\end{abstract}

Materials and methods The data are 34899 hospital discharges with a diagnosis of ruptured or unruptured cerebral aneurysm from 1998 to 2007 identified from the Nationwide Inpatient Sample (NIS). The rates of endovascular coiling and surgical clipping and in-hospital mortality among patients with an aneurysm are examined over a decade by hospital and patient demographic characteristics.

Results From 1998 to 2007, 20134 discharges with a ruptured aneurysm and 14765 discharges with an unruptured aneurysm were identified. Over this decade, the number of patients discharged with a ruptured aneurysm was stable while the number discharged with an unruptured aneurysm increased significantly. The use of endovascular coiling increased at least twofold for both groups of patient $(p<0.001)$ with the majority of unruptured aneurysms treated with coiling by 2007 . Although whites were more likely than non-whites to undergo coiling versus clipping for a ruptured aneurysm $(O R=1.30 ; 95 \% \mathrm{Cl} 1.13$ to 1.48$)$ and men with unruptured aneurysms were more likely than women to undergo coiling ( $\mathrm{OR}=1.26 ; 95 \% \mathrm{Cl} 1.13$ to 1.40$)$, by 2007 differences in treatment selection by gender and racial subgroups were decreased or statistically nonsignificant. Over time the use of coiling spread from primarily large, teaching hospitals to smaller, nonteaching hospitals.

Conclusions The majority of unruptured aneurysms in the USA are now treated with endovascular coiling. Although surgical clipping is used for treatment of most ruptured aneurysms, its use is decreasing over time. Dissemination of endovascular procedures appears widespread across patient and hospital subgroups.

\section{INTRODUCTION}

Cerebral aneurysms are estimated to affect approximately $2 \%$ of the population worldwide. ${ }^{12}$ Rupture of a cerebral aneurysm results in subarachnoid hemorrhage ( $\mathrm{SAH}$ ) and is associated with substantial mortality and morbidity. The rupture rate of an aneurysm is thought to vary with its size, ${ }^{34}$ location $^{4}$ and morphological characteristicss ${ }^{5}{ }^{6}$ as well as a patient's personal and family medical history, ${ }^{48}$ and these variables help to guide the clinical management of these lesions. For those aneurysms requiring treatment, two primary methods are used: microsurgical clipping or endovascular coiling. In 2002, outcomes for patients with ruptured cerebral aneurysms were reported in the International Subarachnoid Aneurysm Trial (ISAT), a randomized, controlled clinical trial that compared the mortality and clinical outcomes of patients with aneurysmal SAH treated with either surgical clipping or endovascular coiling. The study reported that patients who underwent coiling had lower mortality and better outcome at 1 year than those who had open surgery. As a result of this trial, a change in practice pattern within the USA was likely with more ruptured aneurysms treated endovascularly. ${ }^{9} 10$ Although a previous effort to assess this trend through 2003 was presented by Andaluz et al (2008), only now has sufficient time passed since the publication of the ISAT trial results to allow for a formal examination of treatment practice patterns for cerebral aneurysms, both ruptured and unruptured, within the USA. In addition, use of coiling may not be uniform for patients in different demographic subgroups and in hospitals located in different geographic areas. Using data from the Nationwide Inpatient Sample (NIS), we present trends in treatment selection for patients with cerebral aneurysms over the past decade and the associated clinical outcomes.

\section{METHODS}

Data were obtained from the NIS, a component of the Healthcare Cost and Utilization Project (HCUP) sponsored by the Agency for Healthcare Research and Quality and the US Department of Health and Human Services and the largest allpayer inpatient care database in the USA. It contains data on eight million discharges from more than 1000 hospitals each year, which approximates to a $20 \%$ stratified sample of all US community hospitals. ${ }^{11}$ The NIS and other administrative databases have been extensively used to analyze trends of practice in various medical fields in the USA, such as cardiology, ${ }^{12}$ psychiatry, $^{13}{ }^{14}$ gastrointestinal surgery ${ }^{15}$ and spinal surgery. ${ }^{16}$ Here we conducted a retrospective cohort study on data extracted from the NIS to describe trends in treating cerebral aneurysms in the USA. 
Table 1 Descriptive statistics for treated aneurysm discharges from national inpatient sample, 1998-2007

\begin{tabular}{|c|c|c|c|}
\hline Factors & $\begin{array}{l}\text { Ruptured } \\
(n=20134)\end{array}$ & $\begin{array}{l}\text { Unruptured } \\
(\mathrm{n}=14765)\end{array}$ & p Value \\
\hline \multicolumn{4}{|l|}{ Age (years) } \\
\hline Mean $\pm S D$ & $53.3 \pm 13.9$ & $53.0 \pm 14.0$ & \multirow[t]{2}{*}{0.02} \\
\hline Median & 53.0 & 54.0 & \\
\hline \multicolumn{4}{|l|}{ Sex } \\
\hline Female & $13839(68.7)$ & $10665(72.2)$ & \multirow[t]{2}{*}{$<0.001$} \\
\hline Male & $6259(31.1)$ & $4005(27.1)$ & \\
\hline \multicolumn{4}{|l|}{ Race } \\
\hline White & $9073(45.1)$ & 7658 (51.9) & \multirow[t]{4}{*}{$<0.001$} \\
\hline Black & $2297(11.4)$ & $1011(6.8)$ & \\
\hline $\begin{array}{l}\text { Other (Hispanic, Asian } \\
\text { or Native American) }\end{array}$ & $2243(11.1)$ & $1129(7.6)$ & \\
\hline Unknown & $6521(32.4)$ & $4967(33.6)$ & \\
\hline \multicolumn{4}{|l|}{ Income quartile (\%) } \\
\hline$<25000$ & $3626(18.0)$ & $2511(17.0)$ & \multirow[t]{4}{*}{0.006} \\
\hline $25000-34999$ & $5002(24.8)$ & $3687(25.0)$ & \\
\hline $35000-44999$ & $5110(25.4)$ & $3979(26.9)$ & \\
\hline$\geq 45000$ & $5732(28.5)$ & $4234(28.7)$ & \\
\hline \multicolumn{4}{|l|}{ Healthcare coverage } \\
\hline Private insurance & $10412(51.7)$ & $8504(57.6)$ & \multirow[t]{3}{*}{$<0.001$} \\
\hline $\begin{array}{l}\text { Public (Medicare } \\
\text { or Medicaid) }\end{array}$ & $6923(34.4)$ & $5225(35.4)$ & \\
\hline Self-pay & $1797(8.9)$ & $431(2.9)$ & \\
\hline \multicolumn{4}{|l|}{ Charlson comorbidity score } \\
\hline Mean $\pm S D$ & $0.47 \pm 0.73$ & $0.39 \pm 0.65$ & $<0.001$ \\
\hline \multicolumn{4}{|l|}{ Admission source } \\
\hline Emergency room & $9695(48.2)$ & $1020(6.9)$ & \multirow[t]{3}{*}{$<0.001$} \\
\hline Hospital/facility transfer & $6048(30.0)$ & $690(4.7)$ & \\
\hline Elective & $3786(18.8)$ & $12622(85.5)$ & \\
\hline \multicolumn{4}{|l|}{ Treatment method } \\
\hline Clipping & $14514(72.1)$ & $7597(51.5)$ & \multirow[t]{2}{*}{$<0.001$} \\
\hline Coiling & $5620(27.9)$ & $7168(48.5)$ & \\
\hline \multicolumn{4}{|l|}{ Hospital location } \\
\hline Northeast & $3326(16.5)$ & $2595(17.6)$ & \multirow[t]{4}{*}{$<0.001$} \\
\hline Midwest & $4303(21.4)$ & $3523(23.9)$ & \\
\hline South & $7976(39.6)$ & $5686(38.5)$ & \\
\hline West & $4529(22.5)$ & $2961(20.1)$ & \\
\hline \multicolumn{4}{|l|}{ Hospital size } \\
\hline Small & $970(4.8)$ & $879(6.0)$ & \multirow[t]{3}{*}{$<0.001$} \\
\hline Medium & $3019(15.0)$ & $1988(13.5)$ & \\
\hline Large & $16131(80.1)$ & $11894(80.6)$ & \\
\hline \multicolumn{4}{|l|}{ Hospital type } \\
\hline Non-teaching & $3810(18.9)$ & 1902 (12.9) & \multirow[t]{2}{*}{$<0.001$} \\
\hline Teaching & $16310(81.0)$ & $12859(87.1)$ & \\
\hline
\end{tabular}

Approval for the project was obtained from the Partners/ Brigham and Women's Hospital Institutional Review Board. Annual NIS data files from 1998 to 2007 were obtained from the HCUP Central Distributor (Rockville, Maryland, USA). The International Classification of Diseases, Ninth Revision, Clinical Modification $(I C D-9-C M)^{17}$ codes were used to define diagnostic as well as treatment groups. Ruptured aneurysms were defined by code 430.0 (SAH) or 431.0 (intracerebral hemorrhage) and unruptured aneurysms by code 437.3 (cerebral artery aneurysm, not ruptured). Patients with both a ruptured and unruptured aneurysm in one hospitalization were included in the ruptured group. The ICD-9-CM procedure code 39.51 has long been established for microsurgical clipping and was used to categorize those treated by open surgery. For endovascular therapies, dedicated procedure codes 39.72 (endovascular repair or occlusion of head and neck vessels) and 39.79 (other endovascular procedures on head and neck vessels) were defined in 2001.

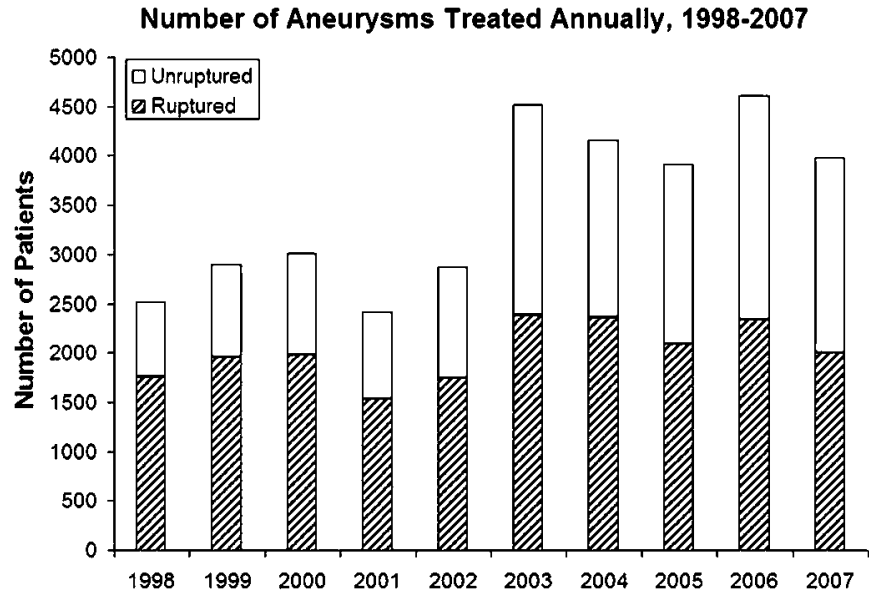

Figure 1 The number of ruptured and unruptured cerebral aneurysms treated annually in the USA, 1998-2007. Although the yearly presentation of ruptured aneurysms was stable, the number of unruptured aneurysms treated in the USA increased significantly during this period.

Before that time, 39.52 (other repair of aneurysm) was used to identify endovascular treatment for a cerebral aneurysm. As the code 39.52 might also include open surgical treatments such as wrapping, in our analyses, patients with code 39.52 were also required to carry a code of 88.41 (angiography of cerebral arteries) and not any procedure codes indicating open craniotomy in the same hospitalization to be categorized as having endovascular coiling. These methods were similar to those described in other investigations of neurosurgical patients. 91018 Only patients with an aneurysm who underwent treatment were included; those who carried diagnostic codes for cerebral aneurysms but not procedure codes for either surgical clipping or endovascular coiling were excluded from analyses. Data from the year 1998, when the NIS sampling and weighting strategy was redesigned to improve national representativeness, ${ }^{19}$ up to the year 2007, the latest database publicly available, were included in the analyses. This period therefore included the 5 years before as well as after publication of the ISAT results.

Differences in demographic and hospital characteristics by diagnostic and treatment groups were examined using $\chi^{2}$ and $t$ tests for binary and continuous variables, respectively. Multivariable logistic regression was used to calculate the ORs and $95 \%$ CIs for the likelihood of using endovascular treatment as well as in-hospital mortality for both SAH and unruptured aneurysm groups after adjusting for age, sex, race (white, black and other), household income quartile, comorbidity score, geographic region, hospital size and hospital teaching status. Medical comorbidity stratification was performed using the Charlson comorbidity index ${ }^{20}$ adapted for use on ICD-9-CM codes. $^{2122}$

Multivariable linear regression was used to examine the association of the above-mentioned variables with postoperative length of stay and total charge for the hospitalization. The NIS categorizes hospital bed size as small, medium and large, based on the hospital's region, location and teaching status, so that approximately one-third of the hospital in a given region, location and teaching status combination would fall into each category. ${ }^{11}$ The NIS database provides information only on the total charge for the inpatient hospitalization, which represents the sum of all charges during the hospitalization except for professional fees. Logarithmic transformation was used for 

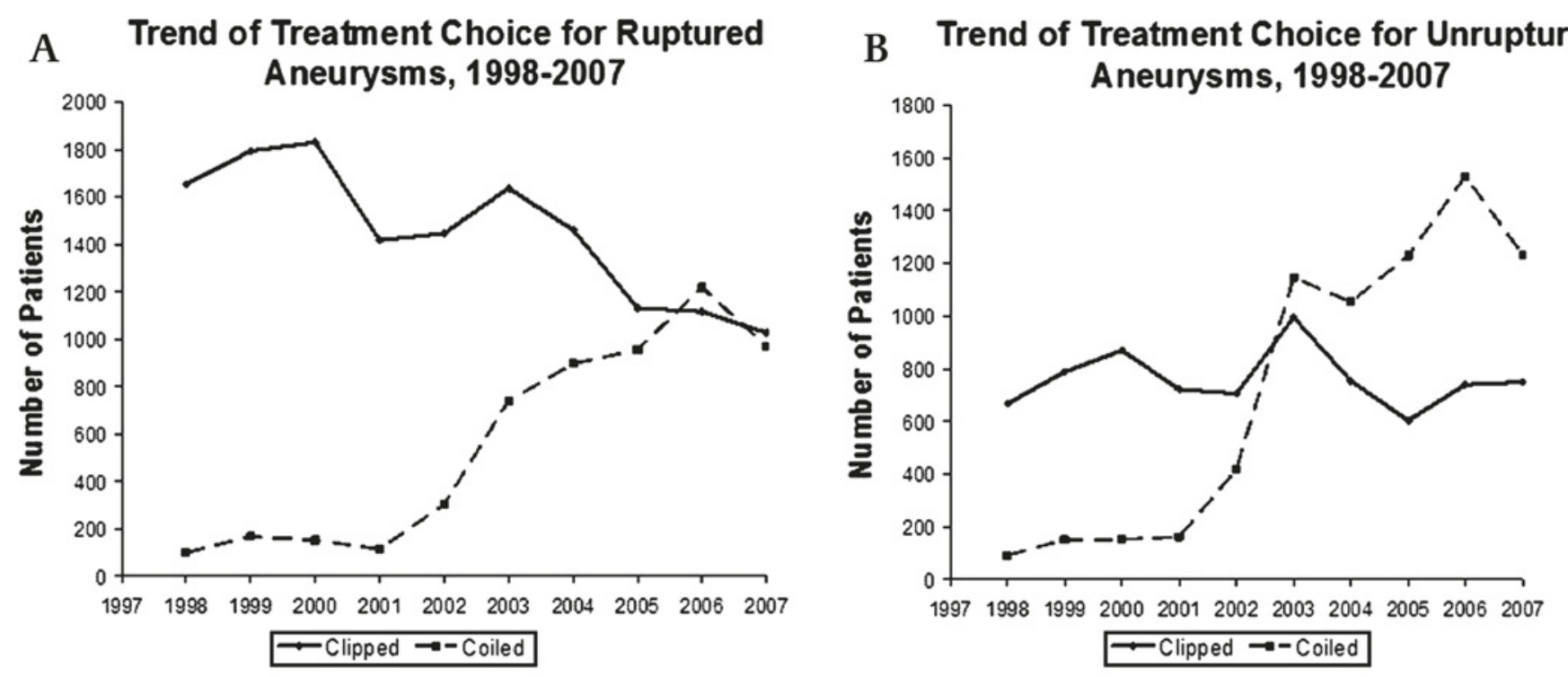

C
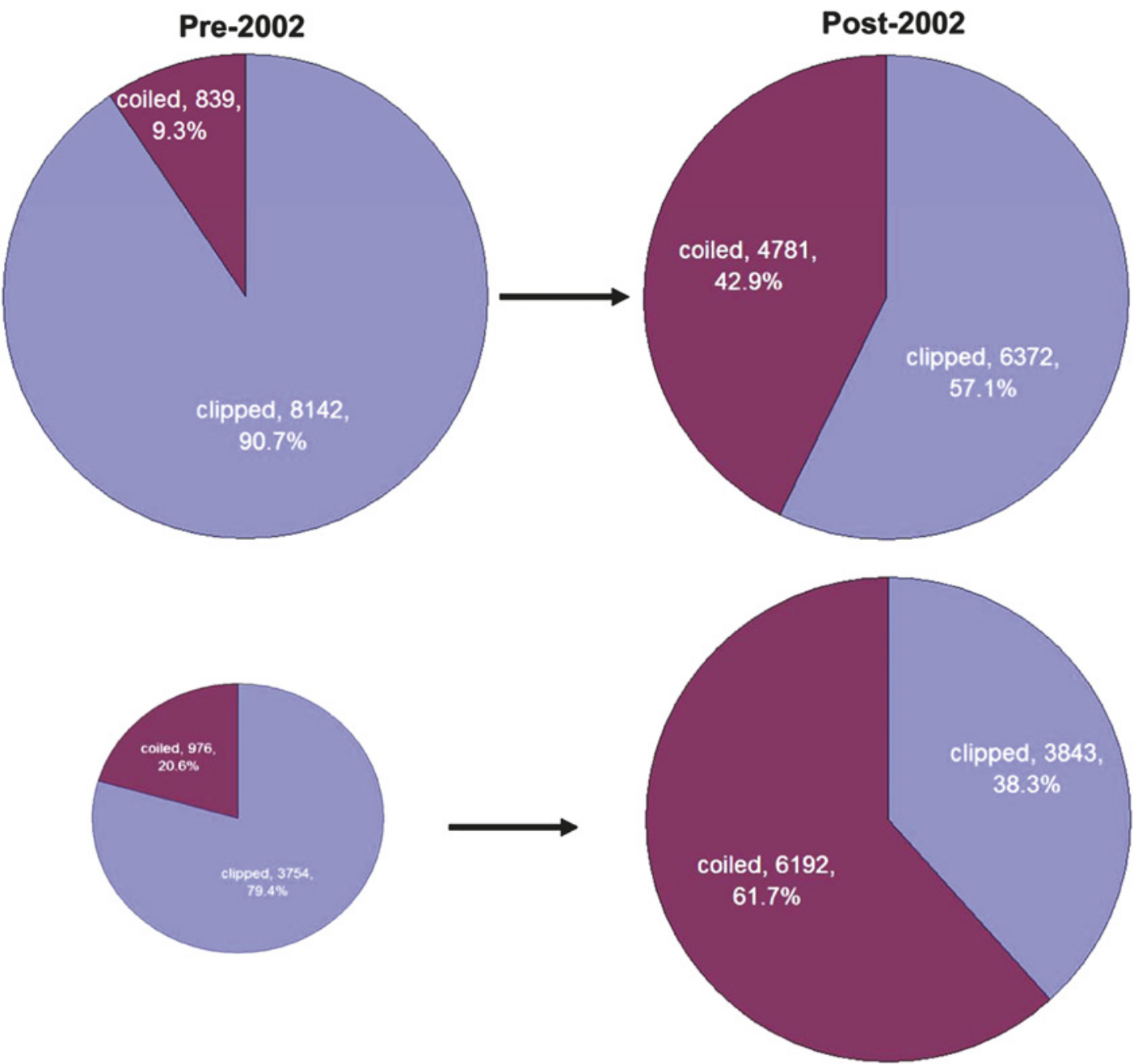

Figure 2 Changes of treatment selection for ruptured and unruptured cerebral aneurysms in the USA before and after the publication of the International Subarachnoid Aneurysm Trial (2002). Increased use of coiling was found for both ruptured aneurysms (A) and unruptured cerebral aneurysms (B) from 1998 to 2007. There was a twofold increase in the use of coiling for both aneurysm types after 2002 (C). 
Table 2 Factors associated with coiling use in ruptured and unruptured aneurysms, NIS 1998-2007

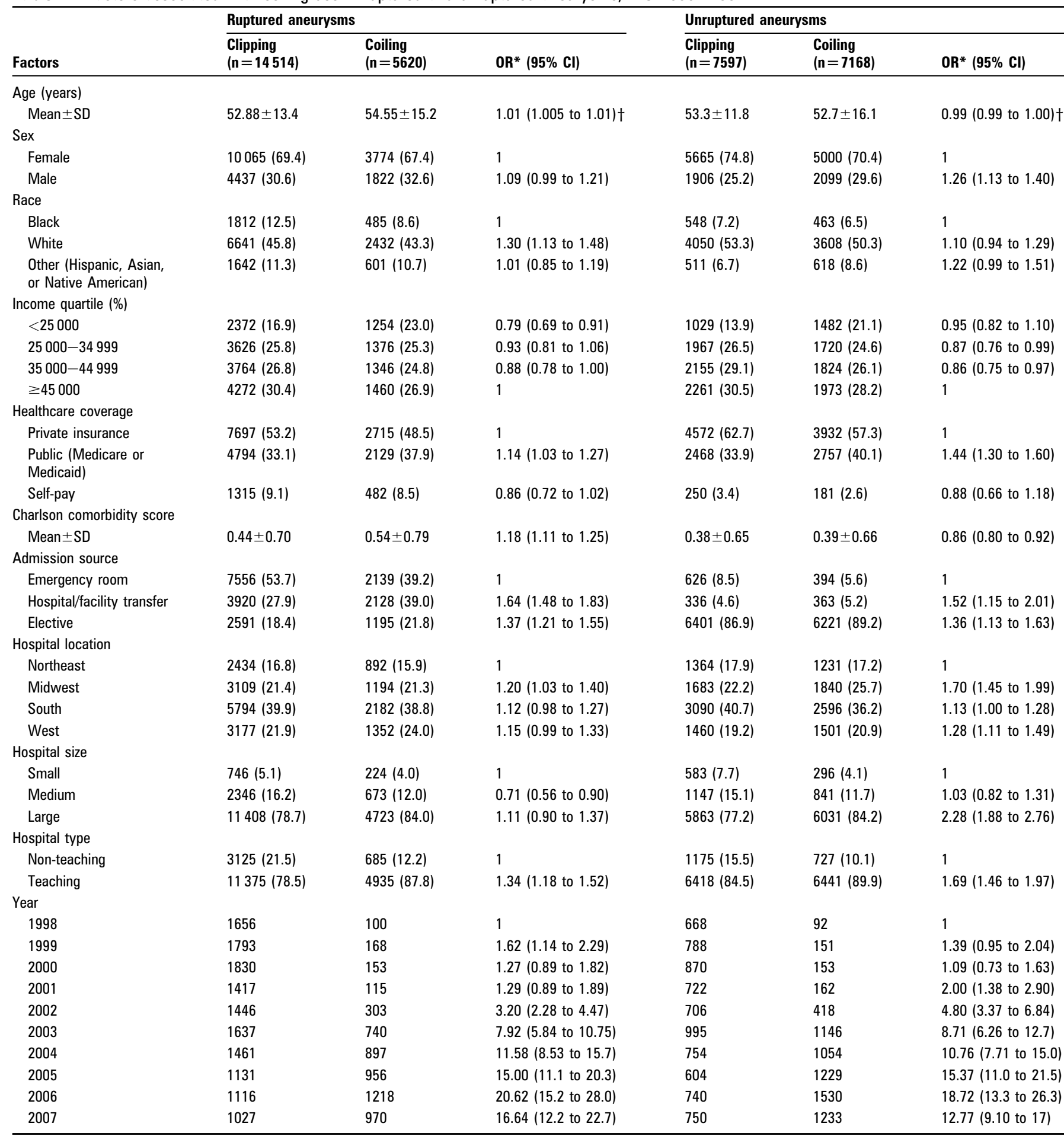

${ }^{*}$ ORs were adjusted for age, sex, race, income quartile, primary payer, admission source, treatment year, Charlson comorbidity score and hospital characteristics (location, size and teaching status).

†OR per year increase.

length of stay and total charges when performing the analyses because of the significant positive skew of the data. Statistical significance was defined as a type I error $<0.05$. Statistical analyses were performed using the unweighted data with SAS version 9.2 (SAS Institute Inc, Cary, North Carolina, USA).

\section{RESULTS}

From 1998 to 2007, 34899 discharges associated with the treatment of a cerebral aneurysm were identified, including
20134 ruptured and 14765 unruptured aneurysms (table 1). The mean age was 53.2 years. The majority of patients were Caucasian and women outnumbered men by at least twofold. Men and non-whites were more likely than women and whites to present as ruptured. Most treatments took place at large medical centers and those with teaching responsibilities. The South had the greatest number of treated patients and private insurance was the most commonly reported payment type. 
Table 3 Trend of factors associated with coiling use in ruptured and unruptured aneurysms, NIS 1998-2007

\begin{tabular}{|c|c|c|c|c|}
\hline \multirow[b]{2}{*}{ Factors } & \multicolumn{2}{|l|}{ Ruptured aneurysms } & \multicolumn{2}{|c|}{ Unruptured aneurysms } \\
\hline & $\begin{array}{l}\text { Before } 20020 \mathrm{R}^{*} \\
(95 \% \mathrm{Cl})\end{array}$ & $\begin{array}{l}\text { After } 2002 \mathrm{OR}^{*} \\
(95 \% \mathrm{CI})\end{array}$ & $\begin{array}{l}\text { Before } 20020^{*} \\
(95 \% \mathrm{CI})\end{array}$ & $\begin{array}{l}\text { After } 2002 \mathrm{OR}^{*} \\
(95 \% \mathrm{CI})\end{array}$ \\
\hline Age & $1.01(1.002$ to 1.018$) \dagger$ & $1.00(1.00$ to 1.01$) \dagger$ & $1.00(0.99$ to 1.01$) \dagger$ & $0.99(0.99$ to 1.00$) \dagger$ \\
\hline Female & 1 & 1 & 1 & 1 \\
\hline Male & 1.38 (1.04 to 1.59$)$ & $1.05(0.94$ to 1.17$)$ & $1.20(0.96$ to 1.50$)$ & $1.27(1.12$ to 1.43$)$ \\
\hline \multicolumn{5}{|l|}{ Race } \\
\hline Other minorities & 1.76 (1.17 to 2.64$)$ & $0.91(0.75$ to 1.09$)$ & 2.16 (1.37 to 3.43$)$ & $1.05(0.83$ to 1.33$)$ \\
\hline \multicolumn{5}{|l|}{ Income quartile } \\
\hline$<25000$ & $1.28(0.85$ to 1.94$)$ & $0.78(0.67$ to 0.90$)$ & $0.79(0.46$ to 1.34$)$ & 0.95 (0.81 to 1.12 ) \\
\hline 25000 to 34999 & 0.85 (0.65 to 1.11$)$ & $0.96(0.83$ to 1.12$)$ & $0.92(0.71$ to 1.20$)$ & $0.86(0.74$ to 1.01$)$ \\
\hline 35000 to 44999 & $0.77(0.60$ to 1.00$)$ & $0.92(0.79$ to 1.07$)$ & $0.82(0.64$ to 1.05$)$ & $0.88(0.76$ to 1.03$)$ \\
\hline Self-pay & $0.80(0.51$ to 1.26$)$ & $0.87(0.72$ to 1.05$)$ & $0.80(1.41$ to 1.59$)$ & $0.91(0.65$ to 1.26$)$ \\
\hline Charlson comorbidity score & 1.28 (1.12 to 1.45$)$ & $1.17(1.09$ to 1.25$)$ & $1.03(0.88$ to 1.21$)$ & $0.84(0.77$ to 0.91$)$ \\
\hline \multicolumn{5}{|l|}{ Admission source } \\
\hline ER & 1 & 1 & 1 & 1 \\
\hline Other facility & 1.66 (1.31 to 2.09$)$ & $1.65(1.47$ to 1.86$)$ & 2.41 (1.40 to 4.14$)$ & $1.27(0.91$ to 1.76$)$ \\
\hline Elective & $1.40(1.07$ to 1.83$)$ & $1.36(1.19$ to 1.57$)$ & 1.56 (1.05 to 2.32$)$ & $1.28(1.03$ to 1.58$)$ \\
\hline \multicolumn{5}{|l|}{ Hospital location } \\
\hline Northeast & 1 & 1 & 1 & 1 \\
\hline Midwest & $1.83(1.31$ to 2.56$)$ & $1.04(0.86$ to 1.24$)$ & 2.58 (1.89 to 3.52$)$ & $1.44(1.20$ to 1.74$)$ \\
\hline South & 1.51 (1.10 to 2.08$)$ & $1.05(0.92$ to 1.21$)$ & $1.29(0.95$ to 1.75$)$ & $1.08(0.94$ to 1.24$)$ \\
\hline West & $1.63(1.17$ to 2.27$)$ & $1.04(0.89$ to 1.22$)$ & 1.80 (1.31 to 2.47$)$ & $1.14(0.97$ to 1.35$)$ \\
\hline \multicolumn{5}{|l|}{ Hospital size } \\
\hline
\end{tabular}

*ORs were adjusted for age, sex, race, income quartile, primary payer, admission source, treatment year, Charlson comorbidity score and hospital characteristics (location, size and teaching status).

tOR per year increase.

The number of aneurysms treated yearly increased significantly during the study period, with treatment of unruptured aneurysms accounting for the majority of the increase (figure 1). For both ruptured and unruptured aneurysms, the trend was toward an increased use of coiling (figures 2A,B). This increase was particularly notable after 2002 when there was a twofold increase in the use of coiling for both aneurysm types. Before 2002, 90.7\% of ruptured aneurysms were treated with clipping versus $57.1 \%$ after $2002(\mathrm{OR}=7.3$; $95 \%$ CI 6.7 to 7.9 ). For unruptured aneurysms, $79.4 \%$ were treated with clipping before 2002 versus 38.3\% after 2002 $(\mathrm{OR}=6.2 ; 95 \% \mathrm{CI} 5.7$ to 6.7$)$ (figure 2C). The number of unruptured aneurysms treated with surgical clipping remained stable over time while the number of ruptured aneurysms that were surgically treated decreased.

We examined factors related to coiling use by rupture status. Across the decade, older age, white race, higher income level, public healthcare coverage, later year of presentation, Midwest location, hospital type (teaching), higher Charlson comorbidity score and non-emergency presentation were significantly associated with coiling for ruptured aneurysms (table 2). In particular, Caucasians who presented with a ruptured aneurysm were more likely to be coiled than blacks (OR=1.30; 95\% CI 1.13

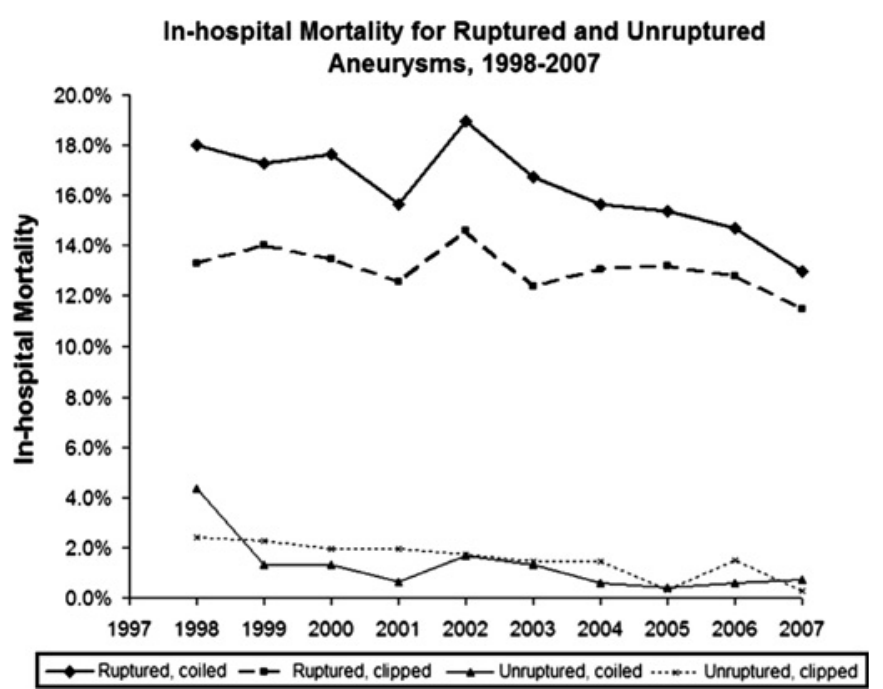

Figure 3 Changes of in-hospital mortality for treated ruptured and unruptured cerebral aneurysms in the USA from 1998 to 2007. Regardless of ruptured status and treatment choice, mortality nationwide decreased steadily over time. 
Table 4 In-hospital mortality according to patient and hospital factors, NIS 1998-2007

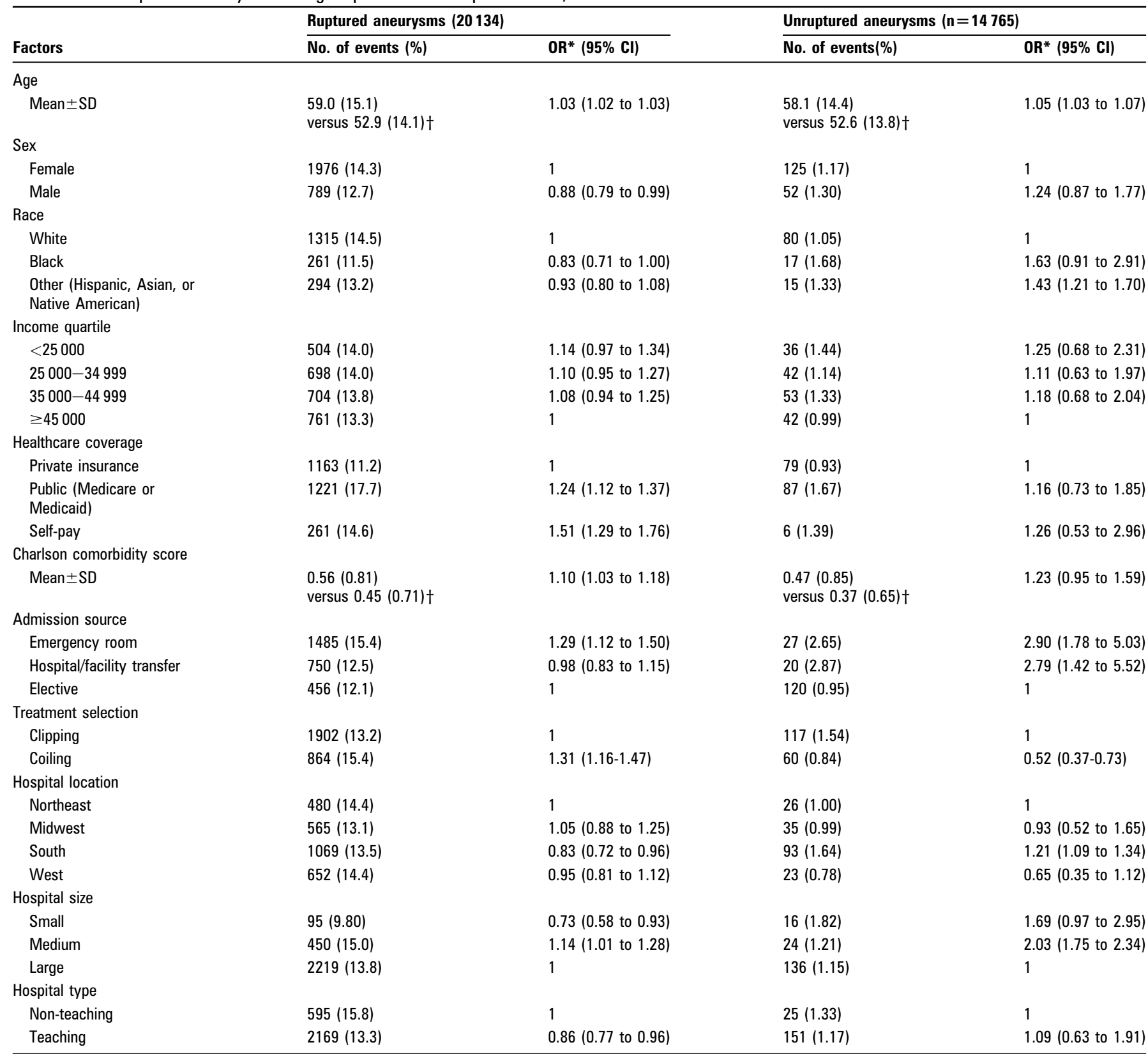

*ORs were adjusted for age, sex, race, income quartile, primary payer, admission source, treatment selection, Charlson comorbidity score and hospital characteristics (location, size and teaching status).

†Mean \pm SD for those who died in hospital versus did not die in-hospital.

to 1.48$)$ and patients with public insurance were more likely to be coiled than those covered by private payers $(\mathrm{OR}=1.14 ; 95 \%$ CI 1.03 to 1.27). For unruptured aneurysms, similar parameters were identified during multivariable analyses except race and Charlson comorbidity score (table 2). In addition, male patients with an unruptured aneurysm were more likely to be coiled than female subjects $(\mathrm{OR}=1.26$; $95 \%$ CI 1.13 to 1.40$)$.

We further investigated whether the above variables associated with coiling usage changed over the decade (table 3). For ruptured aneurysms, the significance of a number of factors lessened over time; in particular, although men were more likely than women $(\mathrm{OR}=1.38 ; 95 \% \mathrm{CI} 1.04$ to 1.59$)$ and whites more likely than blacks (OR=1.68; $95 \%$ CI 1.21 to 2.33$)$ to be coiled before 2002, differences associated with sex (OR $=1.05$; $95 \% \mathrm{CI}$ 0.94 to 1.17$)$ and race $(O R=1.23 ; 95 \%$ CI 1.06 to 1.43$)$ had disappeared or reduced, respectively, after 2002. While large, teaching hospitals performed most of the coiling procedures for ruptured aneurysms before 2002, smaller non-teaching hospitals were equally as likely to perform these procedures after that year. Similar trends were found for unruptured aneurysms, although the tendency for coiling rates to become uniform was less prominent across patient and hospital demographic subgroups over time. For instance, after 2002 men remained more likely than women to be coiled $(\mathrm{OR}=1.27$; $95 \% \mathrm{CI} 1.12$ to 1.43) and coiling was still more frequently performed in large $(\mathrm{OR}=2.14 ; 95 \% \mathrm{CI} 1.72$ to 2.67$)$, teaching $(\mathrm{OR}=1.44 ; 95 \% \mathrm{CI}$ 1.21 to 1.72$)$ and mid-west $(\mathrm{OR}=1.44 ; 95 \%$ CI 1.20 to 1.74$)$ hospitals, although the importance of these factors decreased compared with pre-2002 OR values (table 3).

Overall, in-hospital mortality was $1.2 \%$ for patients with an unruptured aneurysm and $13.7 \%$ for patients with SAH. Regardless of rupture status and treatment choice, mortality 
for treated aneurysms nationwide decreased steadily over time (figure 3). Among patients with ruptured aneurysms, increased mortality was associated with female sex, non-private insurance, higher Charlson comorbidity score, coiling usage and non-teaching hospitals. For unruptured aneurysms, non-elective admission and clipping were associated with a higher mortality (table 4).

\section{DISCUSSION}

In this retrospective cohort study, data from the NIS were used to investigate trends in aneurysm treatment patterns in the USA for the 10-year interval centered around the publication of ISAT in 2002. ${ }^{23}$ A marked change in treatment selection from surgical clipping to endovascular coiling was noted for both ruptured (the focus of the ISAT trial) and unruptured aneurysms after publication of the trial results. The relative increase in coiling usage was greater for patients with SAH than for those with unruptured aneurysms, as the number of ruptured aneurysms treated with surgery decreased while the number of unruptured aneurysms treated with surgery remained stable. The increased use of coiling for both ruptured and unruptured aneurysms is consistent with previous reports, ${ }^{9} 101824-26$ and the large decrease in surgical clipping volume for ruptured aneurysms was recently reported. ${ }^{25}$

These data collectively suggest a paradigm shift for the treatment of cerebral aneurysms within the USA with the majority being treated with endovascular coiling in recent years. While the trend towards more coiling had already occurred in the late 1990s, ${ }^{9}$ publication of the ISAT results markedly accelerated this process in the USA. The trial served to increase the awareness and acceptance of endovascular coiling as a treatment option for cerebral aneurysms in the general public and in the medical community. In 2003, the Center for Medicare and Medicaid Services created a new DRG code (DRG528) for the treatment of intracranial hemorrhage including those caused by aneurysm rupture and both surgical clipping and endovascular coiling were listed as therapeutic options. This addition helped to streamline the billing of coil embolization and may have encouraged its use.

Other factors related to the shift in treatment selection include subsequent technologic advances such as more prevalent usage of stent-assistant coiling, increased availability of endovascular procedures, a shift toward observation rather than surgical intervention for some unruptured aneurysms associated with publication of ISUIA ${ }^{4}$ (hence a different underlying case mix of patients who present for treatment) and financial considerations. Previous analyses by Johnston et al ${ }^{27-29}$ suggest that patients with unruptured aneurysms treated by coiling have fewer adverse events, lower mortality, shorter hospital stay and smaller hospital charge. Hoh et $a^{24}$ also analyzed data from NIS and showed that clipping compared with coiling is associated with significantly longer lengths of stay and higher total hospital charges for patients with ruptured and unruptured aneurysms. Our analyses (not shown) produced similar results, which could influence treatment selection and allocation of hospital resources.

Two studies focusing on the treatment trend for ruptured ${ }^{25}$ and unruptured ${ }^{26}$ aneurysms separately have been published in the past year. Our analyses yielded largely consistent results that the use of endovascular treatment increased considerably for cerebral aneurysms, regardless of rupture status. Furthermore, this study examined practice patterns across race and gender and investigated the changes of these factors over time, both of which had not been previously performed for patients with an

\section{Key messages}

- A change in practice pattern for the treatment of cerebral aneurysms was likely after the publication of the results of the International Subarachnoid Aneurysm Trial (ISAT) in 2002.

- Sufficient time has passed to allow for a formal examination of treatment practice patterns for both ruptured and unruptured aneurysms within the USA.

- Before 2002, 90.7\% of ruptured aneurysms and $79.4 \%$ of unruptured aneurysms were treated with clipping, compared with $57.1 \%$ and $38.3 \%$ after 2002 , respectively.

- Older age, higher income level, public healthcare coverage, teaching hospital admission and non-emergency presentation were associated with a higher likelihood of coiling for both ruptured and unruptured aneurysms.

- Over the past decade, the use of coiling has spread from large, teaching hospitals to smaller hospitals and across all geographic regions. The delivery of care for patients in all gender and racial subgroups has become more uniform over time.

aneurysm in these data. Minorities have traditionally been shown to have poorer access to interventional procedures such as carotid endarterectomy ${ }^{30}$ and coronary angiogram, ${ }^{32}$ which may explain the gap in coiling use between whites and blacks. Men with unruptured aneurysms were more likely to be coiled than women in our analyses, which may potentially be explained by practitioners' tendency to refer women for clipping because female gender is a known risk factor for aneurysm growth and rupture in natural history studies. ${ }^{73}$ However, for the treatment of patients with a ruptured aneurysm, the importance of a number of patient (including sex and race) and hospital demographic factors reduced over time, suggesting a more uniform delivery of care for ruptured patients and a move towards an equitable assignment of treatment across gender and racial subgroups. With respect to hospital demographic characteristics, the use of coiling was seen to spread from more specialized large teaching hospitals to smaller hospitals and across all geographic regions, suggesting a dissemination of this technology away from specialized university-based centers.

Endovascular coiling was associated with lower in-hospital mortality for patients with unruptured aneurysms after adjustment for age, sex and other demographic and hospital factors, although the mortality for either treatment is low. For the SAH group, coiling was found to be associated with higher in-hospital mortality and the difference was consistent over the 10 -year study period (figure 3 ). This finding could be explained by the difference of age and preoperative clinical conditions between the two treatment groups. Patients with SAH who underwent coiling were significantly older $(p<0.0001)$ and had a higher Charlson comorbidity score $(p<0.0001)$ than those who were clipped (table 4). Another counterintuitive finding for the $\mathrm{SAH}$ group was that mortality was lower for patients at small hospitals than for those at medium and large hospitals, which was probably because small hospitals usually transfer highergrade, more complex patients to large, tertiary medical centers.

Caveats for our analyses include the fact that the NIS does not provide specific clinical information on admission, such as the presenting neurological condition, Hunt and Hess grade, or the size and location of the aneurysm and therefore these factors are not included in any analyses. The rationale for treatment 
selection is not known, and no correction was made for associated biases of non-random assignment to treatment. Coding inaccuracies remain a concern for any outcome study using NIS data and ICD-9-CM identifiers ${ }^{34}$; however, the large size and well-established nationwide representativeness made NIS a standard tool for large-sample analyses in multiple medical fields and the codes used here have been previously validated and generally used in examination of treatment of patients with an aneurysm. One difference in our study relative to previous groups is the inclusion of patients with the diagnostic code 431.0 (intracerebral hemorrhage) who also had a procedure code for either clipping or coiling. This group comprised $<10 \%$ of the sample and permitted more complete inclusion of all patients with an aneurysm than previous investigations.

\section{CONCLUSION}

In conclusion, our analyses of the NIS data from 1998 to 2007 highlight the marked increase in coiling use for both ruptured and unruptured aneurysms in the USA, with the majority of unruptured aneurysms now treated with coiling rather than clipping. Endovascular coiling has become more widely available across multiple patient and hospital demographic subgroups.

Funding This work was supported by the Brain Science Foundation, 148 Linden Street, Ste 303, Wellesley, MA 02482, USA.

Competing interests None

Provenance and peer review Not commissioned; externally peer reviewed.

\section{REFERENCES}

1. Oureshi Al, Janardhan V, Hanel RA, et al. Comparison of endovascular and surgical treatments for intracranial aneurysms: an evidence-based review. Lancet Neurol 2007;6:816-25.

2. Rinkel GJ, Djibuti M, Algra A, et al. Prevalence and risk of rupture of intracranial aneurysms: a systematic review. Stroke 1998;29:251-6.

3. Juvela S, Porras M, Poussa K. Natural history of unruptured intracranial aneurysms: probability of and risk factors for aneurysm rupture. J Neurosurg 2008;108:1052-60.

4. Wiebers DO, Whisnant JP, Huston J 3rd, et al. Unruptured intracranial aneurysms: natural history, clinical outcome and risks of surgical and endovascular treatment. Lancet 2003;362:103-10.

5. Raghavan ML, Ma B, Harbaugh RE. Quantified aneurysm shape and rupture risk. J Neurosurg 2005;102:355-62.

6. Dhar S, Tremmel M, Mocco J, et al. Morphology parameters for intracranial aneurysm rupture risk assessment. Neurosurgery 2008;63:185-96; discussion 196-7.

7. Rinkel GJ. Natural history, epidemiology and screening of unruptured intracranial aneurysms. J Neuroradiol 2008;35:99-103.

8. Komotar RJ, Mocco J, Solomon RA. Guidelines for the surgical treatment of unruptured intracranial aneurysms: the first annual J. Lawrence pool memorial research symposium-controversies in the management of cerebral aneurysms. Neurosurgery 2008;62:183-93; discussion 193-4.

9. Andaluz N, Zuccarello M. Recent trends in the treatment of cerebral aneurysms: analysis of a nationwide inpatient database. J Neurosurg 2008;108:1163-9.

10. Cowan JA Jr, Ziewacz J, Dimick JB, et al. Use of endovascular coil embolization and surgical clip occlusion for cerebral artery aneurysms. J Neurosurg 2007; 107:530-5.
11. Overview of the Nationwide Inpatient Sample (NIS). 2010. http://www.hcup-us.ahrq gov/nisoverview.jsp (accessed 1 Aug 2010).

12. Marciniak TA, Ellerbeck EF, Radford MJ, et al. Improving the quality of care for Medicare patients with acute myocardial infarction: results from the Cooperative Cardiovascular Project. JAMA 1998;279:1351-7.

13. Lin RY, Heacock LC, Fogel JF. Drug-induced, dementia-associated and nondementia, non-drug delirium hospitalizations in the United States, 1998-2005: an analysis of the national inpatient sample. Drugs Aging 2010;27(1):51-61.

14. Ilgen MA, Downing K, Zivin K, et al. Exploratory data mining analysis identifying subgroups of patients with depression who are at high risk for suicide. J Clin Psychiatry 2009;70:1495-500.

15. Weber WP, Guller U, Jain NB, et al. Impact of surgeon and hospital caseload on the likelihood of performing laparoscopic vs open sigmoid resection for diverticular disease: a study based on 55,949 patients. Arch Surg 2007;142:253-9; discussion 259.

16. Cahill KS, Chi JH, Day A, et al. Prevalence, complications and hospital charges associated with use of bone-morphogenetic proteins in spinal fusion procedures. JAMA 2009;302:58-66.

17. 2010 ICD-9-CM for Hospitals Volumes 1, 2, and 3. Maryland Heights, MO: Saunders 2009.

18. Hoh BL, Rabinov JD, Pryor JC, et al. In-hospital morbidity and mortality after endovascular treatment of unruptured intracranial aneurysms in the United States, 1996-2000: effect of hospital and physician volume. AJNR Am J Neuroradiol 2003;24:1409-20.

19. Changes in the NIS Sampling and Weighting Strategy for 1998. 2002. http://www hcup-us.ahrq.gov/db/nation/nis/reports/Changes_in_NIS_Design_1998.pdf (accessed 1 Aug 2010)

20. Charlson ME, Pompei $\mathrm{P}$, Ales $\mathrm{KL}$, et al. A new method of classifying prognostic comorbidity in longitudinal studies: development and validation. J Chronic Dis 1987; 40:373-83.

21. Quan H, Sundararajan V, Halfon $P$, et al. Coding algorithms for defining comorbidities in ICD-9-CM and ICD-10 administrative data. Med Care 2005;43:1130-9.

22. Deyo RA, Cherkin DC, Ciol MA. Adapting a clinical comorbidity index for use with ICD-9-CM administrative databases. J Clin Epidemiol 1992;45:613-19.

23. Molyneux A, Kerr R, Stratton I, et al. International Subarachnoid Aneurysm Trial (ISAT) of neurosurgical clipping versus endovascular coiling in 2143 patients with ruptured intracranial aneurysms: a randomised trial. Lancet. 2002;360:1267-74.

24. Hoh BL, Chi YY, Lawson MF, et al. Length of stay and total hospital charges of clipping versus coiling for ruptured and unruptured adult cerebral aneurysms in the Nationwide Inpatient Sample database 2002 to 2006. Stroke 2010;41:337-42.

25. Qureshi Al, Vazquez G, Tariq N, et al. Impact of International Subarachnoid Aneurysm Trial results on treatment of ruptured intracranial aneurysms in the United States. J Neurosurg 2011;114:834-41.

26. Alshekhlee A, Mehta S, Edgell RC, et al. Hospital mortality and complications of electively clipped or coiled unruptured intracranial aneurysm. Stroke 2010;41:1471-6.

27. Johnston SC, Zhao S, Dudley RA, et al. Treatment of unruptured cerebral aneurysms in California. Stroke 2001;32:597-605.

28. Johnston SC, Wilson CB, Halbach WV, et al. Endovascular and surgical treatment of unruptured cerebral aneurysms: comparison of risks. Ann Neurol 2000:48:11-19.

29. Johnston SC, Dudley RA, Gress DR, et al. Surgical and endovascular treatment of unruptured cerebral aneurysms at university hospitals. Neurology 1999;52:1799-805

30. Kapral MK, Wang H, Mamdani M, et al. Effect of socioeconomic status on treatment and mortality after stroke. Stroke 2002;33:268-73.

31. Dardik A, Bowman HM, Gordon TA, et al. Impact of race on the outcome of carotid endarterectomy: a population-based analysis of 9842 recent elective procedures. Ann Surg 2000;232:704-9.

32. Alter DA, Naylor CD, Austin P, et al. Effects of socioeconomic status on access to invasive cardiac procedures and on mortality after acute myocardial infarction. N Eng/ J Med 1999;341:1359-67.

33. Juvela S, Poussa K, Porras M. Factors affecting formation and growth of intracrania aneurysms: a long-term follow-up study. Stroke 2001;32:485-91.

34. Woodworth GF, Baird CJ, Garces-Ambrossi G, et al. Inaccuracy of the administrative database: comparative analysis of two databases for the diagnosis and treatment of intracranial aneurysms. Neurosurgery 2009;65:251-6; discussion 256-7. 